\title{
The need for a national cancer policy in Malawi Yohannie Mlombe ${ }^{1}$, Nicholas Othieno-Abinya ${ }^{2}$, Charles Dzamalala ${ }^{3}$, John Chisi ${ }^{1}$
}

1. Haematology Department, College of Medicine, University of Malawi

2. Haematology and Oncology Section, Department of Clinical Medicine and Therapeutics, College of Health Sciences, University of Nairobi.

3. Malawi National Cancer Registry

Corresponding author : Dr. Yohannie Mlombe, Haematology

Department, College of Medicine, University of Malawi, P/Bag 360,

Chichiri, Blantyre 3, Malawi. Email: yohanniemlombe@googlemail.com,

Phone: +2655276004

\begin{abstract}
Cancer is causing a lot of suffering and death in Africa but is not considered a major health problem in Africa. This needs to change. Cancer should be given equal emphasis to HIV/ AIDS, tuberculosis (TB) and Malaria.

A national cancer policy is required in Malawi to develop and improve evidence-based cancer prevention, early diagnosis, curative and palliative therapy. A national cancer policy is crucial to ensure a priotised, clear, coordinated and sustained fight against cancer. When no policy exists, events are likely to be random, stakeholders and practitioners in the fight against cancer may not agree on how to proceed, may duplicate efforts or may neglect areas that would have greater nationwide impact resulting in poor quality activities and haphazard development.
\end{abstract}

\section{Introduction}

In Africa, cancer is not considered an essential health issue 1 and is not recognized as a major cause of death ${ }^{2}$. Cancer is not mentioned in the Millennium Development Goals (MDGs) ${ }^{3}$; and Malawi's Essential Health Package (EHP) which includes "health services addressing the major causes of death and disease in Malawi" does not include cancer ${ }^{4}$. Official documentation explicitly and implicitly states that EHP only includes funds for priority areas in the health sector in Malawi ${ }^{4}$. In May 2002, the direct annual cost of the EHP components was estimated at nearly US\$83,000,000. This covered:- vaccine preventable diseases; acute respiratory infections in under 5s; malaria; adverse maternal and neonatal outcomes; tuberculosis; acute diarrhoeal diseases; STIs including HIV/AIDS; schistosomiasis; nutritional deficiencies; eye, ear and skin conditions; and common injuries ${ }^{4}$. Cancer was not included as a specific component.

In reality, cancer is a major cause of mortality and morbidity in developing countries. Lack of accurate population based data and the weakness of health information systems mean that there is scarce information on the burden and pattern of cancer in Africa. However, statistical analyses allow us to derive estimates based on few available local data and local studies. The local data itself, even if it were accurate, is likely to grossly under-represent cancer diagnoses owing to lack of capacity to confirm diagnoses. In spite of this, the available estimates should not be ignored. Globocan, a worldwide database deriving estimates from available cancer registries (Malawi National Cancer Registry included), recorded 582,000 cases of cancer in Africa in 2002 and this figure is expected to double in the next two decades if interventions are not intensified ${ }^{5}$. In the same year of 2002, more people died of cancer worldwide (7.6 million) than died of HIV/ AIDS, TB and malaria combined (5.6 million) worldwide ${ }^{6}$.
Although this is a global figure, we can speculate that a measure of success in tackling HIV / AIDS, TB and malaria in the developing world has reduced death rates to levels which are comparable with cancer deaths on account of high case fatality rate for cancers in the developing world. The World Health Organisation (WHO) has estimated that the global cancer burden will increase to 16 million new cases per year by 2020 with $70 \%$ of these occurring in the developing world; Africa will account for more than 1 million of these cases ${ }^{7}$. In Africa in general, the most common cancers in women are cervical cancer and breast carcinoma; and in men are prostate and liver cancer ${ }^{8,9}$. Liver cancer is responsible for the most cancer deaths in men in Africa as a whole?

The available data in Malawi suggests that cancer incidence is increasing in the country. In the pre-HIV era, cancer of the oesophagus $(12.8 \%)$ was reported as the most common cancer in males followed by bladder cancer (7.4\%), Non Hodgkin's Lymphoma (NHL) (7.1\%) and Kaposi's sarcoma (KS) - 6.6\%; whereas in females the most common cancer was cervical cancer $(36.6 \%)$ followed by bladder cancer $(6.8 \%)$ and breast cancer $(6.7 \%){ }^{10}$. The AIDS epidemic has meant that Kaposi's sarcoma is now the most common cancer in Malawi similarly in Uganda, Swaziland, and Zimbabwe ${ }^{7}$.

Blantyre is the only district covered by population based cancer registration in Malawi ${ }^{11}$. In this district, the five most common cancers in order of frequency between 1994 and 1998 in males were KS, cancer of the oesophagus, prostate cancer, liver cancer and bladder cancer/NHL. In females the most common cancers were cervical cancer, KS, cancer of the oesophagus, breast cancer and NHL. In children the most common cancer were lymphoma, retinoblastoma, Burkitt's lymphoma, Wilm's tumour/KS, and connective tissue cancers ${ }^{11}$. In 2002, the three most common cancers in Malawi in order of frequency were:- KS, cervical cancer, and oesophageal cancer ${ }^{5}$. Of note is the fact that Malawi is one of the few countries in Africa where the incidence of oesophageal cancer appears unusually high ${ }^{12}$.

Cancer patients in Africa face a poor outcome ${ }^{13}$. There is a general lack of understanding about the nature of cancer disease. People think it is witchcraft and others do not recognise their tumours or wasting as a serious disease. Society may shun cancer patients resulting in them being too ashamed to seek help. Most patients with cancer present to hospital late ${ }^{14}$.

These cancer trends suggest that unless urgent action is taken to try to control the rising incidence of cancer throughout Africa, thousands of lives will be lost to the disease. The May 2007 London Declaration on Cancer calls on research institutions, international organisations, the pharmaceutical industry, national governments, and civil society in developed and developing countries "to unite and work together to bring comprehensive cancer care to Africa" "15. Communicable diseases should not be neglected, but rather cancer should be given equal priority to diseases such as HIV/AIDS, TB and Malaria - there is no "either or". The two main areas to address in the fight against cancer in Malawi are: (1) reduction of the incidence and mortality of cancer and (2) improvement of the quality of life of cancer patients. 


\section{Reducing the incidence of cancer in Malawi}

In order to effect appropriate measures to reduce cancer incidence, an accurate assessment of the incidence and outcome of cancer is required in Malawi by way of a nationwide population based cancer registration such as the Malawi National Cancer Registry (MNCR). MNCR is based in Blantyre and is the only histopathology service in Malawi, therefore samples from all over the country are sent to Blantyre for data capture. The registry is also able at intervals to make visits to all parts of Malawi to collect cancer data. Population-based cancer data for Blantyre allows for extrapolation of cancer figures for the whole of Malawi. The reliability of MNCR data is questionable owing to (1) histopathology samples from distant places like Chitipa, for example, are not sent to Blantyre with the same frequency as samples from districts surrounding Blantyre; (2) practitioners do not send samples to Blantyre owing to delays and in some cases non-availability of results when samples are sent and; (3) relatively few cancer patients have tissue samples taken owing to shortage of surgery and invasive procedures in the country. Geographic variation in cancer risk factors within Malawi could be identified by having a reliable nationwide population-based cancer registration. Cancer registries need infrastructure, appropriate software and hardware, human resources and training, and incentives for sustainability. MNCR is currently about two years behind in its cancer registration activities owing to funding limitations.

Not all risk factors for cancer in Africa such as increasing life expectancy ${ }^{16}$, are not preventable. However, one-third of cancers are preventable. There is relative prominence of preventable infections as risk factors in Africa ${ }^{17-19}$. Five out of six women with cancer of the cervix live in developing countries ${ }^{6}$. Human papillomavirus (HPV) types 16 and 18 cause $70 \%$ of cervical cancer cases and two vaccines that guard against these HPV types have been developed by the pharmaceutical industry. The availability of these vaccines - still poses many unanswered questions - has immense potential for control of cervical cancer ${ }^{20}$. However, the use of the vaccines in Malawi is hampered by lack of information pertaining to the types of HPV common in Malawi. This needs to be studied.

Antiretroviral therapy (ART) commenced in 2004 in Malawi with a nationwide roll out. ART reduces the acquisition of KS. Up to date data is needed to assess the potential change in the spectrum of cancer disease in the post-ART era in the country.

Hepatitis B (HBV) is endemic on the continent and present in $8-16 \%$ of the general population ${ }^{21}$. Its effect is compounded by widespread exposure to aflatoxin which contaminates staple diets across Africa. Effective strategies are available to reduce the effect of these factors on liver cancer. It is also suspected that the contamination of maize with aflatoxin may contribute to oesophageal cancer ${ }^{22}$.

Tobacco use, which might be small but increasing, is also another preventable factor contributing to cancers in Africa 23. Tobacco exports contribute the most foreign exchange for Malawi's economy. Research is needed to determine the contribution of tobacco to cancer in Malawi before any action can be taken that may needlessly jeopardise the economy. The decreasing number of markets for the tobacco industry in the developed world has two implications for Malawi (1) the tobacco industry may seek to develop new markets in Africa which will lead to increased tobacco use (2) the strength of the Malawi economy may weaken thereby necessitating a shift away from tobacco. Strategies to control tobacco use have included educating civil society (with emphasis on young people, health-care practitioners and policy makers) about the dangers of tobacco use and the benefits of quitting; increasing the tax and price of tobacco; placing of effective warning labels on tobacco products; banning advertising and promotion of tobacco use; prohibiting smoking in public places; banning sales of single cigarettes and prohibiting the sales of tobacco to the youth.

\section{Reducing the mortality of Cancer in Malawi}

Even if all preventive measures were fully implemented today they would have little effect on cancer mortality in the next 10-15 years ${ }^{23}$. Where prevention has failed, early diagnosis may allow cure of cancer with minimal intervention. A third of cancers are treatable if detected early ${ }^{24}$. Screening and cancer awareness campaigns at the primary health care level can facilitate early diagnosis and improve response to therapy $25-26$.

Africa has many logistical and economical limitations. Malawi's economy is very small in size and its gross national income per capita in 2007 was among the lowest ten in the world ${ }^{27-28}$. Thus there are those who argue that for poor countries, emphasis should be on prevention and early diagnosis rather than on therapy. This presents a problem, without offering treatment for cancer, it is difficult for society to adopt prevention and early diagnostic strategies. A more pragmatic approach would be to address prevention, early diagnosis and treatment together.

International league tables have reported in the past, that the UK was ranked lowly in cancer survival tables, had significantly longer treatment waiting times, and fewer cancer specialists and treatment facilities than its European neighbours ${ }^{1}$. This led to the creation of a funded National Cancer Plan. A valuable indicator to assess cancer expenditure in Malawi, is measuring cancer expenditure as a percentage of national income compared with wealthy nations and neighbouring countries.

Basic treatments could achieve cure rates of up to $80 \%$ within a few years. In aggressive non-Hodgkin's lymphoma CHOP (cyclophosphamide, doxorubicin, vincristine and prednisolone) can provide a cure ${ }^{29}$. A $75 \mathrm{~kg}$ patient with a height of $163 \mathrm{~cm}$ would require $1,380 \mathrm{mg}$ of intravenous (IV) cyclophosphamide, $92 \mathrm{mg}$ of IV doxorubicin, $2 \mathrm{mg}$ of IV vincristine and $375 \mathrm{mg}$ of oral prednisolone. At K300 per $500 \mathrm{mg}$ of cyclophosphamide IV, K5,500 per $50 \mathrm{mg}$ IV doxorubicin, K250 per $1 \mathrm{mg}$ IV vincristine and K4 per tablet of prednisolone, the patient in question would require CHOP costing K12,700 every 21 days; which is about K605 per day. Where COP (cyclophosphamide, vincristine and prednisolone) is used for lymphoma ${ }^{30}$, the cost is reduced even further. Cost-effective curative and palliative protocolbased therapies have been shown to be successful in Africa 31,32 .

Treating cancer requires more than just chemotherapy. Ideally, countries should have at least one national cancer centre providing surgery, radiation therapy and chemotherapy. 
Radiation programmes can developed from models provided by the International Atomic Energy Agency (IAEA), and their Programme for Action on Cancer Treatment ${ }^{33}$. The IAEA is already part of ongoing efforts to establish a cancer treatment facility in Malawi ${ }^{34}$. A number of issues need to be considered about this undertaking this includes radiotherapy equipment, radiologists, oncologists, engineers, technicians and nurses among other personnel. Two doctors from Malawi are receiving radiotherapy and oncology training in South Africa, which is commendable.

Most cancers require multimodality therapy, including combinations of surgery, chemotherapy and radiotherapy. This means that comprehensive cancer care needs surgical input (surgical oncologists) and chemotherapy input (medical oncologists/ haemato-oncologists) in addition to radiotherapy. Cancer care is best provided by a multidisciplinary team. In essence a cancer center must be able to provide all the three main modalities of management. It must also be able to provide adequate diagnostic and staging services. Surgical oncology is greatly enhanced where there is availability of pathological intraoperative consultation to provide services such as frozen section procedures, which are currently unavailable in Malawi. For these reasons, it has been suggested that it is better to integrate cancer services into an existing hospital which can provide a multidisciplinary platform for cancer care than establish a stand alone cancer centre. Integration of cancer services into existing hospital services is a realistic approach. Access is also an important consideration. The best diagnostic and staging services in Malawi are concentrated in Blantyre in terms of histopathology and imaging services. This poses several problems for patients in distant districts like Chitipa and Karonga.

\section{Improving the quality of life of cancer patients in Malawi}

Palliative care must be a priority component of affordable and effective cancer care. It provides pain and symptom control, terminal care and bereavement support. It has been suggested that because of limited resources, Africa should concentrate on palliative care alone and forget about chemotherapy and radiotherapy ${ }^{35-36}$. The problem with this line of thought is that it violates health care principles like patient autonomy, prevention of complications of disease, access and equity in provision of care.

Traditional medicine may have a big role to play in palliative care in Malawi, in terms of psychosocial support and should be considered for integration into a national cancer policy. The nature of traditional healer's work enables them to welcome patients that are being shunned by the community ${ }^{37}$. Traditional medical practice encourages openness and patients talk freely. This forum can provide a better understanding of affected person's spiritual, psychological and social needs.

\section{A national cancer policy for Malawi}

In order to effect the measures that would reduce the incidence and mortality of cancer; and improve the quality of life of cancer patients, Malawi needs a national cancer control programme. Governments in Africa must recognise the growing cancer problem and develop cancer control programmes as a matter of urgency. Only two countries in Africa (Cameroon and South Africa) are said to have comprehensive national cancer control policies ${ }^{35}$. There have been two attempts (in 2000 and 2003) to develop a national cancer control policy for Malawi without success. Without a policy, random events, locally available resources, and pressure from special interest groups determine what actions are taken; this can result in poor-quality services and haphazard development.

A national cancer control programme must be developed through a planned process. After considering the problem, the Ministry of Health should issue general directives on planning programmes for cancer control. A national cancer policy would be the basis for planning.

National policy on cancer control was defined by the World Health Organisation (WHO) in 1993 as "an explicit statement of intent by government which defines the objectives of cancer control and the relative priority of each objective; indicates the measures required to attain the objectives; and provides a basis for planning" ${ }^{38}$.

A national cancer policy should be formulated by a national advisory body set up by the Ministry of Health and then approved by an executive authority at the highest level. The membership of the advisory group must include relevant stakeholders. The policy must be based on up-to-date, scientifically sound evidence.

The national cancer policy should contain statements on the objectives of the cancer control programme, a time scale, provision for the facilities needed, the necessary personnel, resources, and funding. Developing a policy is a dynamic process; requiring regular revision based on changes in current knowledge and technology.

The policy should enable integration of priority health areas in Malawi. The EHP and the Sector Wide Approach (SWAp) helps donors assess Malawi's health priority areas. Adding cancer to the EHP would expand competition for limited donor support. On the other hand, cancer could be integrated into existing programmes on HIV/AIDS, TB and Malaria.

Finally, training, education and partnership programmes are of primary importance for both civil society and health practitioners if a cancer care plan is to be successful and sustainable. Priorities include: (1) raising cancer awareness; (2) improving knowledge and capacity through effective partnerships such that expectations are understood and met and that the national policy is sustainable for the future; (3) priority-driven and resource-appropriate research and integration with other programmes; (4) ensuring that education and training programmes cover specialist and generic requirements, from specialist clinical disciplines to research training to healthcare management and operational/ logistical healthcare disciplines, as well as initial and continuing needs.

\section{Recommendation}

In conclusion, Malawi needs a national cancer policy to guide and unify various stakeholder efforts in the fight against an increasing cancer problem. Progressive improvements can be made in cancer control and management by improving areas such as cancer registration, epidemiology, palliative 
care, infra-structure, equipment, personnel and cancer management associated services such as pathology and diagnostic radiology. Instruments such as the EHP and MDGs should be revised to incorporate cancer control ${ }^{5}$.

\section{References}

1. Lingwood RJ, Boyle P, Milburn A, Ngoma , Arbuthnott J, McCaffrey R, Kerr SH and Kerr DJ. The challenge of cancer control in Africa. Nature Reviews Cancer 2008; 8(5):398-403

2. Abimbola, S. Clinton brokers deal to lower price of antiretrovirals. Br. Med. J. 2007; 334:1026

3. UN. The Millennium Development Goals report 2005 http://unstats. un.org/unsd/mi/pdf/MDG\%20Book.pdf (4 February 2008, date last accessed).

4. http://www.lilongwe.mw/ caphill/health/EHPmay2002.htm. Accessed 21st September, 2008.

5. http://www.afro.who.int/dnc/databases/cancer/incidence/index.html. Accessed 20th November, 2008.

6. Stewart, B. W. \& Kleihues, P. (eds). World Cancer Report (International Agency for Research on Cancer, Lyon, 2003).

7. Parkin, D. M. et al. (eds). Cancer in Africa: Epidemiology and Prevention IARC Scientific Publications No. 153 (International Agency for Research on Cancer, Lyon, 2003).

8. Pezzatini, M., Marino, G., Conte, S. \& Catracchia, V. Oncology: A forgotten territory in Africa. Ann. Oncol. 2007; 18:2046-2047

9. Boyle, P. The globalisation of cancer. Lancet 2006; 368:629-630.

10. Hutt MSR. Malawi: register of tumour pathology. 1976-1980. In: Cancer Occurrence in Developing Countries (ed. DM Parkin) IARC, Lyon. 1986: 63-66

11. Banda LT, Parkin DM , Dzamalala CP, Liomba NG. Cancer incidence in Blantyre, Malawi 1994-1998. Tropical Medicine \& International Health. 2001; 6(4):296-304

12. Wapnick S, Zanamwe L. N. D., Chitiyo M., and Mynors JM. Cancer of the Esophagus in Central Africa. Chest. 1972;61:649-654.

13. Kamangar F, Dores GM, Anderson WF. Patterns of cancer incidence, mortality, and prevalence across five continents: defining priorities to reduce cancer disparities in different geographic regions of the world. J Clin Oncol. 2006; 18(12):2048-2049.

14. Stewart, BW.; Kleihues, P. Cancers of the female reproductive tract. WHO Cancer Report. Lyon, France. IARC; 2003: 215-222

15. Serfass L, Van Herpen C, Saghatchian M. Cancer Control in Africa. Eur J. Cancer. 2007; 43(10):1493-5

16. http://www.afro.who.int/ageingandhealth/epidemiology.html. Accessed 20th November, 2008.

17. Ahmed MI, Salahy EE, Fayed ST, El-Hefnawy NG, Khalifa A. Human papillomavirus infection among Egyptian females with cervical carcinoma: relationship to spontaneous apoptosis and TNF-alpha. Clin Biochem. 2001;34:491-498.

18. Youssef AF, Fayad MM, Shafeek AED. Bilharziasis of the cervix uteri. BJOG. 1970;77:847-851.
19. Sayed el-Ahl SA, el-Wakil HS, Kamel NM, Mahmoud MS. A preliminary study on the relationship between Trichomonas vaginalis and cervical cancer in Egyptian women. J Egypt Soc Parasitol. 2002; 32:167-178

20. Agosti JM, Goldie SJ. Introducing HPV vaccine in developing countries-key challenges and issues. N Engl J Med. 2007; 356(19):1908-10.

21. Kramvis A, Kew MC. Epidemiology of hepatitis B virus in Africa, its genotypes and clinical associations of genotypes. Hepatol Res. 2007;37(s1): S9-S19.

22. Sammona AM, Iputob JE. Maize meal predisposes to endemic squamous cancer of the oesophagus in Africa: Breakdown of esterified linoleic acid to the free form in stored meal leads to increased intragastric PGE2 production and a low-acid reflux. Medical Hypotheses. 2006; 67(6): 14311436

23. World Health Organization and International Union Against Cancer. Global Action Against Cancer 2005

24. Parkin, D. M., Bray, F., Ferlay, J. and Pisani, P. Global cancer statistics, 2002. CA Cancer J. Clin. 2005; 55:74-108.

25. Goldie SJ, Kuhn L, Denny L et al. Policy analysis of cervical cancer screening strategies in low-resource settings: clinical benefits and costeffectiveness. JAMA. 2001;285:3107-3115.

26. Hartley P, Daubenton JD. Curing Cancer in children-early recognition and appropriate treatment are the key, S Afr Med J. 2001; 91: 40-42.

27. http:// siteresources.worldbank.org/DATASTATISTICS/Resources/ GDP.pdf. Accessed 26th September, 2008

28. http:/ / siteresources.worldbank.org/DATASTATISTICS/Resources/ GNIPC.pdf. Accessed 26th September, 2008.

29. McKelvey EM, Gottlieb JA, Wilson $\mathrm{HE}$ et al. Hydroxyldaunomycin (adriamycin) combination chemotherapy in malignant lymphoma. Cancer 1976;38:1484-1493.

30. Bagley CM, De Vita VT, Berard CW, and Canellos GP. Advanced lymphoma intensive cyclal combination chemotherapy with cyclophosphamide, vincristine, and prednisolone. Ann Intern Med 1972;76:227-234.

31. Pettersen F, FIGO annual report of the results of the treatment of gynaecological cancer, Int J Gynaecol Obstet 1991; 36:72.

32. Sur RK, Levin CV, Donde B et al., Prospective randomized trial of HDR brachytherapy as a sole modality in palliation of advanced esophageal carcinoma-an International Atomic Energy Agency study, Int J Radiat Oncol Biol Phys. 2002; 53:127-133.

33. UICC World Congress 2008. IAEA/PACT Joins Global Cancer Community to Declare War on Cancer. http://cancer.iaea.org/newsstory.asp?id=44 Accessed 26th September, 2008

34. Malawi's bold initiative to tackle cancer treatment. http://cancer.iaea.org/ newsstory.asp?ft $=0$ Accessed 26th September, 2008

35. Morris K. Cancer? In Africa? Lancet Oncol. 2003; 4(1):5

36. Williams M, Wakehamb K. Radiotherapy might not be the answer in Africa. Lancet Oncol. 2006; 7(9):705

37. Kayombo EJ, Mbwambo ZH, and Massila M. Role of traditional healers in psychosocial support in caring for the orphans: A case of Dar-es Salaam City, Tanzania. J Ethnobiol Ethnomed. 2005; 1: 3.

38. The development of guidelines for the design of national cancer control plans: report on a WHO Working Group. Copenhagen, WHO Regional Office for Europe, 1983 (unpublished document ICP/CAN 014). 